\title{
Upper Primary Teachers' Perceptions of PSLE English Oral Assessment
}

\author{
Norashikin Binte Mohamed Noor \\ James Cook University (Singapore) \\ Tel: 02-656-312-5059Ｅ-mail: norashik@jcu.edu.sg \\ Mohan K. Muniandy \\ Universiti Teknologi MARA (UiTM) \\ Academy of Language Studies, Kuala Pilah Campus, 72000 Kuala Pilah, Negeri Sembilan, Malaysia \\ Tel: 60-6-483-2130/60-12-611-8478 E-mail: mohan691@.ns.uitm.edu.my \\ Shashi Kumar Krishnan@ Shanmugan \\ Universiti Teknologi MARA (UiTM) \\ Academy of Language Studies, Kuala Pilah Campus, 72000 Kuala Pilah, Negeri Sembilan, Malaysia \\ Tel: 60-6-483-2182/60-12-323-6945 E-mail: shash011@ns.uitm.edu.my \\ Emily Jothee Mathai \\ Universiti Teknologi MARA (UiTM) \\ Academy of Language Studies, Penang Campus, 13500 Permatang Pauh, Pulau Pinang, Malaysia \\ Tel: 60-4-382-3366/60-16-480-5649 E-mail: emily_j@ppinang.uitm.edu.my
}

\begin{abstract}
This small scale study investigated upper primary teachers' perceptions of the PSLE English oral assessment. It sought to find out the challenges that teachers faced in conducting PSLE English oral assessment and if the assessment format provides a good gauge of pupils' oral competence. Semi-structured interviews were the main research instruments used in this study. The data collected was analysed quantitatively and qualitatively. Findings from the data showed that there is heterogeneity in teachers' views of the PSLE English oral assessment. The study found that 1) there is much variance in the challenges identified by teachers; 2) there are limited common perceptions among teachers regarding the extent that PSLE English oral assessment is a good gauge of pupils' oral competence; and 3) teachers are for the idea of review and modifications to the current PSLE assessment format however, they did not make any concrete suggestions for improvement.
\end{abstract}

Keywords: PSLE (Primary School Leaving Examination), Oral assessment, Perceptions

\section{Background}

Language is the most salient form of communication. Oral skill, as a verbal form of communication, is an important facet of pupils' language proficiency. However, assessing oral skills is a challenge. Various cognitive and metacognitive processes are involved as pupils respond during an oral assessment. The challenge in assessing oral communication is more prevalent in an assessment setting where verbal exchanges from pupils must be audible and intelligible for examiners. The inability of examiners to decode verbal responses can be detrimental to the grades received by pupils.

In Singapore, all pupils taking the Primary School Leaving Examination (PSLE) have to sit for a homogenous oral assessment. In 2005 the Ministry of Education made a revision to the PSLE oral assessment format and added a conversation component to the existing picture conversation and reading components. This revision led to the increasing demand on oral examiners to provide an unbiased assessment of pupils' oral performance. Examiners would need to have a certain level of competence to elicit and assess pupils' responses. However, English communication in Singapore can be a challenge to both pupils and examiners. Multilingual Singaporean pupils' responses could display features of the English language with interferences from their native or home languages. There could also be interferences from Singapore English or Singlish which "differs from Standard English in form and use". (Alsagoff \& Ho, 2003, p.283).

\section{Research problem}

This small scale study sought to investigate the perceptions of upper primary (primary 3 to primary 6) teachers of the PSLE English oral assessment. Teachers' perceptions and beliefs are an essential part of improving teaching preparation and effectiveness. Through this investigation, some insights can be gleaned on the extent teachers' 
perceptions have a backwash effect on their classroom teaching practices. (Tunku, 2005 p.208).

Though schools in Singapore are now given more autonomy in determining the extent of the speaking component to be taught, pupils still have to sit for the same national examinations at the end of their primary school education. At present, primary schools assess pupils' oral skills by adopting a format similar to the PSLE English oral assessment. During the assessment, pupils have to depend on their schema and prior knowledge to be effectively engaged in a thematically bounded conversation with the examiners. Pupils, however, process their thoughts in different ways and not all are able to be articulated successfully or as successfully as others do. This lack of correlation between cognition and speaking could result in a breakdown of thoughts conveyed by pupils during the oral assessment. Assessing oral competence is a complex and covert process. Many features of oral competence are being assessed in an oral assessment. These features include fluency, self-corrections, grammatical accuracy and syntactic complexity. During an oral assessment, examiners have to chart a relationship between all these features, match pupils' responses to the marking descriptors and give appropriate grading to them. The complexity of assessing oral competence is increased further through such procedures.

PSLE oral assessment is mainly a summative assessment. Examiners are guided by a set of descriptors and their own experience in assessing pupils' oral performance. The subjective nature of oral assessments can be regarded as a threat to their reliability. The occurrence of inter-rater reliability or the measure in which examiners judge the same pupil's responses in the same way, (Mackey \& Gass 2005, p. 129) is possible during PSLE oral assessment since each pupil is examined by two examiners simultaneously. Differences of perceptions between examiners can pose problems in the grading process. Mackey and Gass (2005, p.242) suggest that oral examiners should be carefully selected and trained. In Singapore, training for PSLE oral examiners is brief and usually conducted nearing the assessment period. Teachers' ability as an oral examiner however, is not formally assessed after the training.

This study in turn aims at answering the following questions:

i. What do teachers perceived as challenges and problems in evaluating and assessing pupils' oral performance?

ii. What are the perceptions of teachers regarding the extent of the PSLE oral assessment in providing an accurate measure of pupils' oral competence?

iii. What do teachers perceived as suggestions that could improve the PSLE oral assessment format to be an accurate measure of pupils' oral competence?

\section{Literature review}

Oral competence is a form of life skill. It is a tenet of linguistic proficiency and is an important communication tool. Recent years have seen a surge of researchers documenting on the increasing importance of oral communication and issues related to its assessment. (Eg. Dornyei, Z. \& Kormos, J. 2000 \& Oliver, Haig \& Rochecouste 2005). However, to the best of my knowledge, research in oral communication assessment in Singapore, particularly at the Primary level, has been modest and scarce. This is surprising since the Ministry of Education have revised the PSLE oral assessment format in 2005. In view of this, studies in the area of oral assessment, especially among Singapore primary schools, definitely deem more attention. Moreover, research in oral communication in terms of its pedagogy and assessment has been an ongoing interest among linguists and educators in Australia, US and the UK. For example, Oliver, Haig \& Rochecouste (2005) have investigated issues relating to the challenges secondary schools' teachers and pupils in Western Australia faced in assessing and sitting for an oral assessment, respectively.

Linn and Gronlund (1996, p.5) define assessment as "the full range of procedures used to gain information about student learning and the formation of value judgements concerning learning progress." Singapore primary schools' oral assessment context seems to adhere to this definition by creating three oral components, namely reading, picture description and conversation. Despite these various components, its ability to provide a credible judgement of pupils' oral skills is still debatable. A recognised caveat of oral assessments is the unreliability of performances across teachers or across time for the same examiners (Linn \& Gronlund, 1996, p.243). Due to the time consuming nature of oral assessments, one cannot disregard fatigue factors of the examiners as affecting their ability to give an objective rating for a subjective assessment.

Though descriptors and rubrics are given to examiners, logical errors committed by them are discounted by the descriptors and rubrics. This error concerns examiners' belief when two characteristics are treated as more alike or unalike (Linn \& Gronlund, 1996, p.252). For example, examiners assessing pupils from the gifted programme could overrate them and underrate pupils from other streams. Another concern of oral assessments would be personal bias (Linn \& Gronlund, 1996, p.252) among examiners. This occurs when examiners tend to rate all pupils with approximately the same rating. In PSLE oral assessment, the situation is exacerbated by the low total marks (10 marks) for each component. 
Assessments are characteristically stressful. Stress will have an adverse impact on pupils' emotional state and in turn affect their voice quality, tone, pitch, volume and tempo. (Petty, Petty \& Salzer, 1999 p. 122 \& Bygate, 2001 p.16). During oral assessments, these features are largely considered in the grading criteria. If these features carry significance importance in grading, then test design and scoring rubrics should also have equitable bearing on the stress factors impacting pupils. The features of oral communication go beyond speech production. Hand gestures, body movements and facial expressions are nonverbal aspects of oral communication that are spontaneously coordinated with speech. (Petty, Petty \& Salzer, 1999 p. 123 \& Young 2002, p. 249). Although paralinguistic behaviour and other features, for example seeking clarifications, are equally important in an oral interaction, these are not criteria of PSLE oral assessment .Young's (2002) study of discourse approaches to oral assessment highlights the failure of some assessments to include any consideration of oral language as interaction. PSLE oral assessment format displays this lack of consideration since pupils are required to engage in the communicative event individually and prompted only by the examiners when it is deemed necessary.

The oral assessment situation in Singapore is compounded by the multi-lingual demographics of its pupils. Instruction in most Singapore primary schools is mediated through Singapore Standard English. However; the sine qua non of an English language class here is that the language used is usually not the pupils' first language. Even if English is being used, Singapore English or the Singlish variety is chosen. This variety is marked for its grammatical inaccuracies. The choice of this language variety is not encouraged during an oral assessment where correct and grammatical sentence constructions are of paramount importance. This leads us to the question whether oral assessments are aimed at testing linguistic competencies or communicative competencies. Gupta (2003) has focused on the communicative practice among teachers and pupils on the variety of English used to achieve mutual intelligibility. She has provided evidence of communication breakdown between teachers using Singapore Standard English and pupils using the lower variety of English or Singlish. Eventually the latter was chosen by some teachers to ensure mutual intelligibility and facilitate understanding with pupils. If mutual intelligibility is an important aim of oral communication, why does grammatical adherence has a large bearing in oral assessments? This leads to a major debate on the extent that oral assessment aims at testing speaking as opposed to testing language proficiency (Hughes 2002, p.75). The choice of language variety is not the only reason contributing to communication breakdown. Schleppegrell and Dudgeon's (1996) research of sixty $3^{\text {rd }}$ and $6^{\text {th }}$ grade pupils and seven of their teachers in Virginia USA, reports that pupils' and teachers' differing expectations and beliefs of successful oral communication in the classroom can contribute to this breakdown. With regards to oral assessment, if examiners' expectations and beliefs are not explicitly articulated to pupils prior to the assessment, it could prove detrimental to their (pupils') oral performance and grading. Hughes (2002) supports this view when he argues that in language testing, oral assessment objectives must be made explicit so that any ambiguity between speaking proficiency and language proficiency can be carefully discerned by examiners and pupils.

Canale and Swain (1980), cited in Weir (1990, p.9), argues that oral assessments should test pupils' linguistics knowledge and their ability to demonstrate communicative competence in purposeful setting. Similarly, Underhill (1987) in Hughes $(2002$, p73) states that "a genuine oral test is when real people meet face to face and talk to each other." PSLE oral assessment is certainly not an authentic communicative event. The rigid format of the PSLE oral assessment excludes the consideration of real-life demands during speaking and interaction. Speaking and oral communication are naturally people focused, while assessment is more language focused (Hughes 2002, p.73). The reciprocal nature of speech demands more on speakers' communicative competence than linguistic competence. It is therefore of optimal importance to consider the demands of speaking and testing in crafting oral assessments to correctly reflect pupils' oral competence. As recommended by Weir (1990), oral testing and assessment should be reflective of situations that pupils might encounter in their own real-life situations.

Often in Singapore, pupils' oral competence is judged in terms of their successful performance in the biannual semestral oral assessment. This assessment format is summative in nature and is usually similar to the PSLE. It mostly considers pupils' knowledge of topics and linguistic features of their responses. Clearly it indicates a general lack of awareness of the interactive function of oral communication. This contrasts Bygate's (1987) notion, as cited in Hughes (2002, p.48), that "oral communication needs to be conceptualised as a skill rather than as knowledge". The format also does not make apparent the communicative competence on the part of examiners. An examiner's role as an interlocutor during an oral assessment is equally important. Examiners' prompting and questioning techniques must be able to elicit responses from pupils. As highlighted by Hughes (2002, p.79) and Bygate (2001, p.16) the success of oral communication depends on how speakers (examiners and pupils) have a communicative effect on one another. However, due to unauthentic settings of assessments, flow of natural speech between examiners and pupils could be restricted. Also, as pupils become socialised and acquainted to the language of oral assessment, they become aware of a host of linguistics, communicative and behavioural features that contribute to 
their success in the assessment. But is this success reflective of their skills in a natural spoken discourse? This in turn gives rise to the question if the current assessments in Singapore primary schools reflect pupils' test-taking techniques or genuine oral skills.

\section{Data collection}

The method used to answer the research questions involved semi-structured interviews. Verbal reports were recorded from semi-structured interviews with 10 teachers who are experienced PSLE English oral examiners .Interviewing is one of the common methods of data collection (Mackey \& Gass 2000, p. 167). Semi-structured interview, as a mode of data collection, was chosen as it would allow the researcher to decide the main topics to be discussed before the interview. The researcher would have the flexibility to decide on the topics prior to the interview and to work out the detailed structure during the interview process (Drever, 1995). Semi-structured interview in turn gives the interviewee the freedom to decide what to talk about, how much to say, and how to express it. Prior to the interview, a pilot study was conducted with two teachers. The main aim of the pilot study was to try out the feasibility and productivity of the interview schedule. The pilot study also helped the researcher to test and make final revisions on the method of data collection (Mackey \& Gass 2005, p. 43).

Interviews with the teachers were conducted within 2 weeks after a PSLE oral assessment. This was to ensure that interviewees were able to rely effectively on their short-term memory of the PSLE oral assessment experience. The interviewees are upper primary English language teachers, teaching primary 5 or primary 6 classes. Since speaking is typically reciprocal, the teachers were invited to be interviewed in pairs. Pairing the interviewees would enable them to contribute simultaneously to the interview and to comment and respond to each other's perceptions (Bygate, 2001, p.16; Hughes 2002, p.73).

A set of pre-prepared topics guided the interviewer in eliciting teachers' perceptions. The topics focused on teachers' perceptions of the important components of oral skills, challenges in conducting the assessment and PSLE oral assessment format. Interviewees were also required to rate their confidence and competence in conducting oral assessment using a 5 point Likert Scale (Brown \& Rodgers 2002, p. 120). The 5 point scale was chosen to minimize a biased scoring since an even point scale might force interviewees to choose a more positive or negative response.

\section{Methods of analysis}

Audio-recordings of the interview sessions were transcribed. The transcribed data were then counted and coded for recurring themes. The recurring themes were analysed qualitatively and quantitatively. The frequency, repertoire and patterns from the recurring themes were tabulated or represented graphically. Responses by teachers with different length of teaching experience were also compared. This comparison would help the researcher to identify marked responses unique to a particular group of teachers.

\section{Teachers' perceptions}

\subsection{Teachers' perceptions of importance of oral communication.}

All 10 teachers expressed the belief that oral communication is an important component of linguistic proficiency. The teachers provided some reasons behind this belief. Table 1 shows a summary of the reasons given by the teachers. The teachers had varied views of the importance of oral communication. There were 6 recurring themes as identified by the teachers. 6 teachers identified 'the need to be understood' as one of the important reasons for oral communication while 3 teachers perceived that language is mostly in the spoken form.

\subsection{Teachers perceived features of oral communication}

This question was crafted with the intention of gauging teachers' repertoire of the different features of oral communication. Table 2 shows features identified by the teachers. 14 features were identified by the teachers with each teacher identifying an average of 3 features. The teachers also identified para-linguistic and phatic features of oral communication. 'Intonation' as a feature of oral communication, had the highest frequency with 7 teachers identifying it. However, it is interesting to note that only 1 teacher (T7) identified 'listening' as a feature of oral communication.

\subsection{Teachers' perceptions of PSLE English oral assessment format}

Teachers were asked to comment on the current PSLE oral assessment format. The teachers went on further to provide elaborations for their choice. These elaborations were coded and summarized in Tables 3.1 to 3.3 .

\subsection{Teachers' perception of challenges in conducting PSLE oral assessment}

Teachers expressed their perceptions concerning challenges involved in conducting PSLE oral assessment. The frequency of these challenges is shown in Figure 1.4 teachers identified 'unresponsive pupils' and their examining 
partners as challenges in conducting PSLE oral assessment. 'Personal bias' as a challenge in assessment was identified by 1 teacher. This respond is crucial to the next topic in the interview schedule.

\subsection{Teachers' perceptions of the influence of pupils'physical appearance on grading}

2 teachers perceived physical appearance as sometimes contributing to their overall assessment. It was also observed that these 2 teachers have been teaching for less than 4 years. This is in contrast to 8 teachers who responded as never being influenced by physical appearances. 5 of these teachers have at least 4 years of teaching experience.

\subsection{Teachers 'perceptions of oral testing competence and confidence}

With regards to oral testing competence and confidence, 9 teachers gave themselves a positive rating of either 3 or 4 out of a total 5 points. These 9 teachers however were unable to give a convincing rationale for their rating and cited their modest personality as the main reason for their choice. Only 1 teacher gave herself a rating of 5 and attributed it to her overseas education and exposure to native-English speakers. Regarding teachers' perception of the need for training, 9 teachers agreed that training on how to conduct oral assessment at the upper primary level is necessary. They described the rationale for this in the following manner:

- To assist teachers in oral grading.

- To help teachers who lack oral skills.

- To explore new ways of oral assessment.

- To understand the marking rubrics and descriptors.

- Teachers have differing understanding of oral skills.

- Teachers should be trained before they can train pupils.

- Oral communication is a life skill. It will benefit teachers and pupils.

- To keep themselves abreast with the Ministry of Education initiatives and directives.

- Teachers devote the least amount of curriculum time to oral skills as compared to reading and writing.

Only 1 teacher was unsure and not in favour of training. Her rationale was that schools could not cope with too many teachers being away for courses. This rationale is however, more of a logistics than a linguistics concern.

\subsection{Teachers' perceived suggestions on modifications to PSLE oral assessment}

8 teachers welcomed the possibility of modifications on the current PSLE oral assessment format. Only 1 teacher deemed it to be unnecessary since the oral component does not contribute extensively to the overall English marks. Another teacher took a neutral stance. His lack of expertise in crafting oral assessment and his confidence in the Ministry of Education examination policies contributed to his non-committal stance. Surprisingly, no teacher gave any concrete suggestions on ways to improve the assessment format.

\section{Findings and discussion}

There are two findings from the data. i) There is variance in teachers' beliefs and perceptions of the extent that the PSLE English oral assessment format is a reliable measure of pupils' oral competence. ii) The teachers have various perceptions of the challenges they face in conducting PSLE oral assessment. One theme that clearly emerged from the findings is that teachers' belief of the importance of oral communication stems from the need to be understood among language users (Haig, Oliver \& Rohecouste 2005, p.7). Teachers did not equate the importance of oral communication and its increased emphasis to just the academic context. One teacher even cited the need to achieve economic goals as contributing to the importance. Teachers' beliefs provide insights to their broad view of the need for oral communication. The beliefs would impact both their practices in the classroom. Choice of pedagogy, oral features to be taught and selection of instructional materials are affected by the beliefs. Further, their beliefs could cascade down to pupils and form an impetus for them (the pupils) to realise the importance of developing oral skills as part of life skills.

\subsection{Teachers' perceptions of challenges in conducting PSLE oral assessment}

Considering the first research question, inspection of the data suggests that there is heterogeneity of teachers' beliefs about challenges in conducting the oral assessment. One challenge of oral assessment described by teachers is the given descriptors. Though examiners are given descriptors and scoring rubrics, not all those interviewed have common understanding of these. Making fine distinctions from the rubrics and descriptors given is a matter of professional judgement. It has been argued, even by the teachers in this study, if the descriptors and rubrics are able to describe the performance of all pupils involved in the same assessment (Tunku 2005, p.205) and if they assess all, if not, most aspects of oral communication. 
Some teachers identified unresponsive pupils as a challenge. Tunku $(2005$, p.205) argues that pupils are unresponsive when they could not understand what is heard. Lewis (2006, pp.259-263) suggests that comprehensibility is dependent on the ability of the listener to comprehend. This study supports their view with some reservations, specifically if pupils or examiners do not reach a mutual understanding, there will be some pupils' response but this will influence the performance rating. Examiners carry the responsibility for initiating and prompting responses. Pupils' main duty is to comply and answer (Luoma 2004, p.29). Moreover, pupils' unresponsiveness reflects examiners' prompting cues rather than pupils' comprehension. Either they were unable to craft prompts to support pupils' responses or the suggested prompts given to the examiners were not adequate or appropriate. Further, pupils' hesitation before responding cannot automatically be taken as insecurity or lack of knowledge (Hughes 2002, p. 82). The issue of examiners' communicative competence may be the factor. It is clear from this study that not all teachers are confident of their communicative competence.

A very significant finding is teachers' acknowledgement of bias towards pupils' physical appearance and how they speak. Pupils with native-speakers' like pronunciation are perceived as better. This leads to the debate on whether appearance and native-speakers' like speech take precedence over all other communicative considerations. Though there is no known research of how teachers in Singapore regard this variety of speech, we can safely assume this attitude serves only to marginalise pupils further since not all of them are exposed and can emulate native- speakers' like speech.

The sociocultural dimension of oral assessment interaction, further highlighted in this study, suggests that pupils' success in assessments is affected by their own and examiners' expectations which are rarely made explicit. This is in resonance to Schleppegrell and Dudgeon (1996) study on pupils' and teachers' awareness of a good answer, which reveals that differing beliefs of communicative success between examiners and pupils could lead to unsuccessful communication. The situation is exacerbated when examiners have differing expectations of pupils' performance.

\subsection{Teachers' perceptions of PSLE English oral assessment format as a reliable measure of pupils' oral competence}

The second research question investigated teachers' perceptions of the extent that the current PSLE English oral assessment format provides a good gauge of pupils' oral competence. The semi- structured interview raised the issue of the incapability of the current format to test the many aspects of oral communication. Teachers feel that the picture discussion and conversation components in the oral assessment only provide a general measure of pupils' oral skills. Teachers argue that pupils' ability to contribute to them is dependent on their (pupils') life experiences. Gerson (2006, p.271) supports this view and states that "second language ability is not situated in the learners' mind but in a multitude of sociocultural and institutional settings... to which the learner has been exposed throughout his/her life." This reflects the gap of oral assessments in testing pupils' ability to converse as opposed to their life experiences. Major considerations should be made in deciding the conversation topics and picture as these could be foreign to pupils. They have to be constrained within familiar cultural context, are child-friendly or child-focused and reflect the general interest of pupils in Singapore.

Teachers who view the PSLE oral assessment format as a good format of assessment attributed this to its demand on testing pupils' ability to think on the spot. This elaboration only sheds light to the disregard that some teachers have on stress factors pupils face during the assessment. Stress impacts pupils' emotional state and ability to think on the spot adversely. Consequently their voice quality, tone, pitch, volume and tempo will be affected. (Petty, Petty \& Salzer, 1999 p. 122, Bygate, 2001 p.16). During an oral assessment, thinking on the spot might not be manifested through pupils' articulation. Teachers must be made to realise that it is the latter that is tested not the former.

\subsection{Teachers' perceived suggestions for improving PSLE English oral assessment format}

The third research question found a limited degree of responses by the teachers. Though the teachers agree that the PSLE oral assessment format should be modified, they did not make any significant suggestions. 2 generalisations can be derived from this. i) Teachers are not informed of various oral communication testing tools and; ii) teachers assumed that contributing towards external assessment is not within the realms of their teaching responsibilities.

\section{Implications on teaching and assessment}

The results of the study provide considerable evidence that teachers have varied perceptions towards the current PSLE oral assessment format. These perceptions could have a consequential effect on their teaching and expectations of pupils.

\subsection{Summative nature of PSLE oral assessment}

PSLE oral assessment is summative in nature and is void of the diagnostic element towards pupils' learning and oral skill development. The format seems to be imposed on all pupils who have to invariably meet a particular standard 
of performance mandated by the scoring rubric. The assessment procedures do not provide teachers the opportunity to provide feedback on pupils' performance. Due to such characteristic of the assessment, the onus is now on teachers to make a conscious effort in their daily assessment of pupils' oral skills, to communicate extensively with them and to provide feedback of their (pupils) oral performance.

\subsection{Pedagogical considerations}

Though how teachers employ their PSLE oral assessment experience into their classroom teaching was not investigated in this study, one cannot deny that teachers' experiences would influence their teaching and impact pupils' learning. This view is echoed in Dobinson's (2001) study of pupils learning from classroom interactions. She argues that pupils do learn from their teachers. The learning process can be expedited if teachers present pupils with meaningful oral skills opportunities. Educators and curriculum planners have drawn extensively from Vygotsky's Sociocultural Theory (1978), as cited in Lyle (2002), who emphasised that children construct their understanding and knowledge in dialogical manner with others. This teacher-pupil interaction will present pupils with different perspectives and experiences that will help them to build up on their own schema and verbal repertoire (Hodges, Moss \& Shreeve, 2000). This is not to say that there is no place for teaching pupils' mastery of isolated features of speech, what is of more pedagogic concern is the predominance of such instructions in English classes and the extent they replicate authentic communicative setting .

\subsection{Teachers' awareness of metalanguage associated with oral communication}

There is evidence of a narrow view amongst the teachers of what constitutes oral language. The data reveals that teachers mainly identified features of speech production rather than interactive features of oral communication. No teacher articulated on the non-verbal aspects of oral communication. The gap between teachers' metalanguage of oral communication and its interactive function is apparent here. The belief that oral communication only entails verbalised aspect has proven to be a misconception. Speaking is interactive in nature (Hughes 2002, p.73). Hand gestures, body movements and facial expressions are nonverbal aspects of oral communication that are coordinated with speech (Young 2002, p.249). PSLE oral assessment did not make any attempts to assess such non-verbal features. The findings from this study echo the findings of Haig, Oliver and Rohecouste (2005) regarding teachers' lack of awareness about the complexity of oral communication. The study indicates that the lack of awareness in oral communication leads to unsuccessful teacher-pupil interaction.

\section{Conclusion}

This small scale study has attempted to adopt a novel approach to investigate teachers' perceptions of the current PSLE oral assessment, by addressing some common concerns. This is an integral point in the study as the concerns and issues raised by teachers will impact their grading and assessment of pupils. In reference to the research questions posed, it has been found that there is a link connecting teachers' perceptions of the oral assessment format, their own beliefs of oral communication and their own oral assessment experience in determining pupils' performance. Findings from this study provide the general support for the position that PSLE English oral assessment format should be reviewed and teachers be trained and re-trained on oral communication skills. The study also demonstrates that oral language assessment gives very little emphasis to the wide range of other aspects of oral communication, in spite of current and future needs as acknowledged by the teachers.

The emphasis on English proficiency and its assessment is constantly changing. It is proposed that teachers be exposed to new assessment procedures and technology to help them adapt to the changes. Besides the mechanics of assessment, there is also a need to understand its discourse. As Young (2002) points out, the discourse in oral language is complex and the issue of understanding second language learner in an oral language assessment still remains a challenge. The complexity of oral language testing is compounded by the fact that it is being concerned with pupils' knowledge of English language and vocabulary and how to use it in a meaningful communicative setting. (Morrow 1979, Canale \& Swain 1980 as cited in Weir 1990 \& Luoma 2004, p. 57).

Singapore education trend is now geared towards making teaching more pupil-centred .It is therefore logical to make assessments more pupil-centred as well. This study is in accord with Fulcher and Reiter (2003, p. 339) view which stresses on the necessity for designers of (PSLE) oral assessment to look to pragmatic concerns and cultural factors in crafting assessment materials, with appropriate descriptors and rating scales. Curriculum planners and educational policy makers have to be progressive of their support for more holistic and experiential types of curriculum and assessment activities.

\section{References}

Brown, A. (2000). Singapore English in a nutshell. An alphabetical description of its features.Singapore. Federal Publications.

Bygate, M. (2001).Speaking. In R. Carter and D. Nunan (eds) The Cambridge guide to teaching English to speakers 
of other languages. Pp14-20.

Dornyei, Z. \& Kormos, J. (2000). The role of individual and social variables in oral task performance. In Language Teaching Research 4(3), pp 275-300.

Dobinson, T (2001). Do learners learn from classroom interaction and does the teacher have a role to play? Language Teaching Research. 5 (3 ), pp. 189-211.

Foster, P., Tonkyn, A. Wigglesworth, G. (2000). Measuring spoken language a unit for all reasons. Applied Linguistics, 21(3), (pp 354-375). Oxford University Press.

Fulcher, G. (2003). Testing second language speaking. (chp7). Great Britain Pearson/Longman.

Fulcher, G. \& Reiter, R.M (2003). Task difficulty in speaking tests. Language Testing 20 (30) (pp. 321-344).

Gupta, A. (2003). A framework for the analysis of Singapore English. In G. Saravanan, \& Pakir (Eds.) Language, Society and Education in Singapore, (pp 119-132). Marshall Cavendish International.

Haig, Y., Oliver, R. \& Rochecouse, J. (2005). Communicative competence in language assessment In Language and education. 19(3), pp. 212-222.

Ho, CL. \& Lubna, A. (2003). Is Singlish grammatical?: Two notions of grammaticality. In G. Saravanan \& A. Pakir (Eds.) Language, Society and Education in Singapore, (pp 281-290). Marshall Cavendish International.

Hodges, G., Moss, J. \& Shreeve A. (2000). The Future of English. English in education 34: 1-10.

Hughes, R. (2002). Teaching and Researching Speaking. (Chp 4-5). Great Britain. Pearson Education.

Gerson, M.J. (2006). Local and dialogic language ability and its implication for language teaching and testing. In Spoken English, TESOL and Applied Linguistics. Challenges for Theory and Practice. pp.245-270.

Lewis, J. M. (2006). Pronunciation and the assessment of spoken language. In Spoken English, TESOL and Applied Linguistics. Challenges for Theory and Practice. pp.245-270.

Luoma, S. (2004). Assessing speaking. Cambridge University Press. Chp 3 (pp. 29-57).

Lyle, S. (2002). Talking to learn: The voices of children, aged 9-11, engaged in role play. In Language and Education 16(4), pp303-315.

Mackey, A., \& Gass, S. M. (2005). Second language research: Methodology and design. Mahwah, NJ: Lawrence Erlbaum

Petty,D.C., Petty, W.T. \& Salzer, R.T. (1999). Experiences in language. Tools and techniques for language arts methods.( Chp 5). Massachusetts: Paramount Publishing.

Schleppegrell, M.J \& Simich-Dungeon, C. (1996). What's a good answer? Awareness about behavioural and content features of successful classroom interaction. Language in education. 10(4), (pp 273-286).

Tunku M. (2005). Teachers perceptions towards oral assessment and their implications for teaching. In J. Foley (Ed.), New Dimensions in the Teaching of Oral Communication Anthology Series, (pp.205-223). Singapore. SEAMEO Regional Language Centre.

Weir, J. (1990). Communicative language testing. Prentice Hall International UK.

Young, R. (2002). Discourse approaches to oral language assessment. Annual Review of Applied Linguistics (22), (pp 24-262).

Table 1. Teachers' belief about the importance of oral communication

\begin{tabular}{|c|c|c|c|c|c|c|c|c|c|c|}
\hline & T1 & T2 & T3 & T4 & T5 & T6 & T7 & T8 & T9 & T 10 \\
\hline $\begin{array}{l}\text { To be understood/ To communicate with others/ /To put } \\
\text { ideas across/ To communicate with people from different } \\
\text { language backgrounds }\end{array}$ & -- & + & + & -- & + & + & + & + & -- & -- \\
\hline Language use is mainly in the spoken form. & -- & + & + & -- & -- & -- & -- & -- & + & -- \\
\hline To prevent miscommunication/not to be misunderstood & + & -- & -- & + & -- & -- & -- & -- & -- & -- \\
\hline $\begin{array}{l}\text { To keep up with the increasing emphasis on oral } \\
\text { competency. }\end{array}$ & - & + & -- & -- & -- & -- & -- & -- & + & -- \\
\hline Part of English communicative competence. & -- & + & -- & -- & -- & -- & - & -- & - & - \\
\hline Economic goals & -- & -- & -- & -- & -- & -- & - & -- & -- & + \\
\hline Number of reasons given by each teacher. & 1 & 4 & 2 & 1 & 1 & 1 & 1 & 1 & 2 & 1 \\
\hline
\end{tabular}


Table 2. Perceptions of teachers concerning the features of oral communication

\begin{tabular}{lllllllllll}
\hline & T1 & T2 & T3 & T4 & T5 & T6 & T7 & T8 & T9 & T 10 \\
\hline 1. Intonation & + & - & + & + & + & - & - & + & + & + \\
2. Fluency & + & - & + & - & - & - & - & + & - & + \\
3. Expression & + & - & - & + & + & - & - & - & - & - \\
4. Pauses & + & - & + & - & - & - & - & - & + & - \\
5. Pronunciation & - & - & - & - & - & - & - & + & + & - \\
6. Sentence structure & - & + & - & - & - & - & - & - & - & + \\
7. Vocabulary & - & - & + & - & - & - & - & - & - & - \\
8. Questioning techniques & - & - & - & + & - & - & - & - & - & - \\
9. Audibility & - & - & - & - & + & - & - & - & - & - \\
10. Turn taking & - & - & - & - & - & + & - & - & - & - \\
11. Body gestures & - & - & - & - & - & + & - & - & - & - \\
12. Diction & - & - & - & - & - & - & + & - & - & - \\
13. Listening & - & - & - & - & - & - & + & - & - & - \\
14. Intelligibility & - & + & - & - & - & - & - & - & - & - \\
\hline Number of features identified by & $\mathbf{4}$ & $\mathbf{2}$ & $\mathbf{4}$ & $\mathbf{3}$ & $\mathbf{3}$ & $\mathbf{2}$ & $\mathbf{2}$ & $\mathbf{3}$ & $\mathbf{3}$ & $\mathbf{3}$ \\
each teacher. & & & & & & & & & \\
\hline
\end{tabular}

Table 3.1 Teachers who perceived the PSLE oral assessment format to be good.

\begin{tabular}{|l|l|l|}
\hline & Teachers' Elaborations & Teacher Responded \\
\hline 1. & Tests fluency & $\mathrm{T} 2, \mathrm{~T} 8$ \\
\hline 2. & Picture discussion allows pupils to converse widely & $\mathrm{T} 2, \mathrm{~T} 9$ \\
\hline 3. & Prompts provided allow pupils to converse widely. & $\mathrm{T} 5, \mathrm{~T} 8$ \\
\hline 4. & Tests ability to think on the spot. & $\mathrm{T} 5, \mathrm{~T} 8$ \\
\hline 5. & Test pupils' speaking skills. & $\mathrm{T} 2$ \\
\hline 6. & Tests intonation & $\mathrm{T} 2$ \\
\hline
\end{tabular}

Table 3.2 Teachers who perceived the PSLE oral assessment format not to be good.

\begin{tabular}{|l|l|l|}
\hline & Teachers' Elaborations & Teacher Responded \\
\hline 1. & $\begin{array}{l}\text { Pupils with limited life experiences could not contribute to conversation } \\
\text { component. }\end{array}$ & $\mathrm{T} 1, \mathrm{~T} 6$ \\
\hline 2. & Picture component has no relevance & $\mathrm{T} 1$ \\
\hline 3. & Picture just test on identifying of graphics. & $\mathrm{T} 4$ \\
\hline 4. & Pupils' speech is unnatural/ Pupils don't speak in that manner & $\mathrm{T} 6$ \\
\hline 5. & It's not valid to test pupils' 6 years of education within 20 minutes. & $\mathrm{T} 7$ \\
\hline
\end{tabular}

Table 3.3 Teachers who are unsure if the PSLE oral assessment format is good.

\begin{tabular}{|l|l|l|}
\hline & Teachers' Elaborations & $\begin{array}{l}\text { Teacher } \\
\text { Responded }\end{array}$ \\
\hline 1. & $\begin{array}{l}\text { Too many aspects of oral communication. } \\
\text { PSLE does not assess all. }\end{array}$ & $\mathrm{T} 3$ \\
\hline 2. & PSLE too stressful for pupils/intimidating for pupils to face 2 adult strangers. & $\mathrm{T} 3$ \\
\hline 3. & Performance on picture component depends on pupils' familiarity. & $\mathrm{T} 10$ \\
\hline 4. & $\begin{array}{l}\text { Performance on conversation component depends on pupil's familiarity to topic/ Conversation } \\
\text { based on experience. }\end{array}$ & $\mathrm{T} 10$ \\
\hline
\end{tabular}




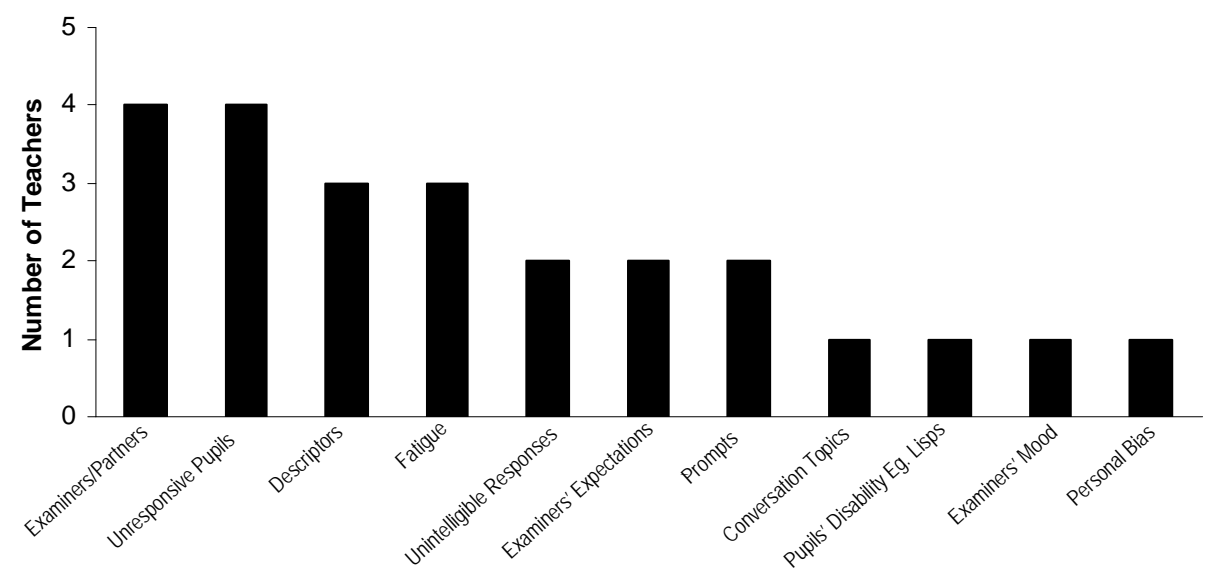

Figure 1. Teachers' perceived challenges in conducting PSLE oral assessment 